\title{
A Novel Mechanism for Harmonic Reduction in Single Source Isolated Buck-Boost Hybrid Multilevel Inverter
}

\author{
Md Saleh Ebn Sharif ${ }^{1, ~ *, ~ S . ~ M . ~ R a f i u l ~ I s l a m ~}{ }^{1}$, Md Monower Zahid Khan², Md Eliasinul Islam³, \\ Mohammad Shakil Khan ${ }^{4}$ \\ ${ }^{1}$ Department of Electrical \& Electronic Engineering, Bangladesh University of Engineering and Technology, Dhaka Bangladesh \\ ${ }^{2}$ Department of Electrical and Electronic Engineering, The University of Manchester, Manchester, UK \\ ${ }^{3}$ Department of Electrical, Electronic \& Communication Engineering, Military Institute of Science \& Technology, Dhaka, Bangladesh \\ ${ }^{4}$ Institute of Energy, Dhaka University, Dhaka, Bangladesh
}

Email address:

saleh.electrical07@gmail.com (Md S. E. Sharif)

${ }^{*}$ Corresponding author

\section{To cite this article:}

Md Saleh Ebn Sharif, S. M. Rafiul Islam, Md Monower Zahid Khan, Md Eliasinul Islam, Mohammad Shakil Khan. A Novel Mechanism for Harmonic Reduction in Single Source Isolated Buck-Boost Hybrid Multilevel Inverter. International Journal of Sensors and Sensor Networks. Vol. 7, No. 2, 2019, pp. 28-33. doi: 10.11648/j.jjssn.20190702.13

Received: August 5, 2019; Accepted: August 29, 2019; Published: September 17, 2019

\begin{abstract}
Traditional Hybrid Multilevel inverter produces $(2 n+1)$ levels at output voltage of inverter for $n$ number of sources by a switching mechanism which requires $4 \mathrm{n}$ number of switches. However, one underlying problem of single phase multilevel inverter is that it requires isolated sources which render it inappropriate except where isolated energy sources are available. In this paper, firstly, a new technique is proposed for generating multiple isolated Buck-Boost DC sources of variable voltages from a single DC source. Secondly, a new switching algorithm is proposed by which number of output voltage levels can be increased by $80 \%, 157 \%$ and $833 \%$ while reducing number of switch count by $0 \%, 16.66 \%$ and $25 \%$ keeping voltage stress across the switches unhampered for two, three and four source inverter respectively compared to traditional multilevel inverter. As a result, conspicuous improvement is achieved in terms of harmonic distortion dropping it down to $4 \%$ and less than $1 \%$ for three and four source inverter respectively even without using output filters or sinusoidal PWM switching signals. A meticulous analysis of the circuit configuration and switching algorithm along with detailed performance analysis is provided throughout the paper.
\end{abstract}

Keywords: Hybrid Multilevel Inverter, Simulated Annealing, THD, Fuzzy Logic, Harmonics Reduction

\section{Introduction}

Multilevel inverter has become popular especially in high power applications due to its inherent capability of reducing voltage stress across semiconductor devices. At the same time, multilevel inverter is capable of producing higher output voltage which contains lesser harmonics and subharmonics [1]. Most popular inverter topologies in recent literature have been diode-clamped multilevel inverter (DCMLI), flying capacitor multilevel inverter (FC-MLI) and cascaded H-bridge multilevel inverter (CHB-MLI) [2]. Among these, intuitive arrangement of CHB-MLI facilitates reduced circuit components, flexible low frequency switching techniques, low electro-magnetic interference and better output frequency spectrum [1].
Traditional CHB-MLI requires $\mathrm{n}$ isolated DC sources for an output voltage which exhibits $(2 n+1)$ discrete voltage levels which precludes its universal implementation for high power applications [5]. Leon M. Tolbert adopted a pragmatic approach by using a single DC source with the remaining (n1) dc sources being capacitors $[3,7]$. One inherent problem with that configuration is that it offers limited control over capacitors voltage as the capacitors are charged as a part of overall current flow. As capacitors are charged to an equal voltage levels, output voltage can only obtain limited discrete values. An adroit switching arrangement can increase number of voltage levels, hence reducing harmonic distortion. This approach demands unequal source voltage for each hybrid inverter block [4-9]. Moreover, it does not maneuver to determine optimum values of sources which exhibit lowest 
harmonic distortion in output voltage. High frequency PWM signals can be used to reduce THD instead of increasing discrete voltage levels, but it hampers one fundamental advantage of MLI [11-15]. It would increase device rating, switching loss and overall efficiency as a result of high frequency switching.

In this paper, a systematic approach is introduced to overcome some of the existing drawbacks of traditional CHB-MLI while simultaneously improving power quality in terms of frequency spectrum. Firstly, isolated DC sources are generated from a single DC source by slightly modifying typical Buck-Boost circuit arrangement and connecting them parallel. Traditional way is to generate isolated sources by using tapped transformer and traditional Buck-Boost circuit. But, transformer generally aggravates circuit efficiency and it makes the circuit bulky. Typical Buck-Boost circuit is shorted together at the ground with the source; as a result parallel connection would not isolate the sources. Modified circuit arrangement offers isolation while maintaining the flexibility of changing output voltage by varying duty cycle to the pulse. A non-linear artificially intelligent fuzzy logic controller monitors output voltage of the DC-DC converters. Secondly, an optimization algorithm, Simulated Annealing, determines best possible combinations of source voltages which collectively generate minimum distortion at output voltage of inverter. A pulse generator circuit correspondingly generates suitable pulsing signals for the switching block. New switching scheme allows creating as many voltage levels as can be generated from all possible combinations of summation and subtraction from isolated sources. As increased number of levels can be generated, overall harmonic distortion in output wave shape is reduced tremendously. Thirdly, inverter circuit arrangement is slightly modified to reduce total number of switches used for the inversion. As a consequence, cost, weight, size and other corresponding attributes of the overall circuit reduces and reliability and longevity of the package increases.

\section{Proposed Methodology}

Proposed methodology can be divided into three broad categories: 1) Buck-Boost circuit Block 2) Decision making and Pulse generation circuit 3) Hybrid inverter block. First block consists of parallel connected modified Buck-Boost converters along with corresponding control circuitry and functionalities comprising Fuzzy logic and Simulated Annealing. Simulated Annealing (SA) is an optimization algorithm which is activated only upon any change to the desired peak voltage of output voltage of inverter. It calculates such subsets of voltages whose combinations deliver minimum distortion in inverter output provided that cumulative summation is equal to the desired peak of output voltage. Fuzzy Logic Block maintains the actual voltage of the DC-DC converters to the desired levels by changing the duty cycle of the pulse. Pulse generation and control circuitry consists of decision making and switching time estimation, Interrupt and ADC functionality, general I/O and Optocoupler isolation. Inverter Block consists of cascaded inverter legs. Switching Pulse along with the isolated voltage sources is supplied to inverter block which generates a multilevel output at the laod.

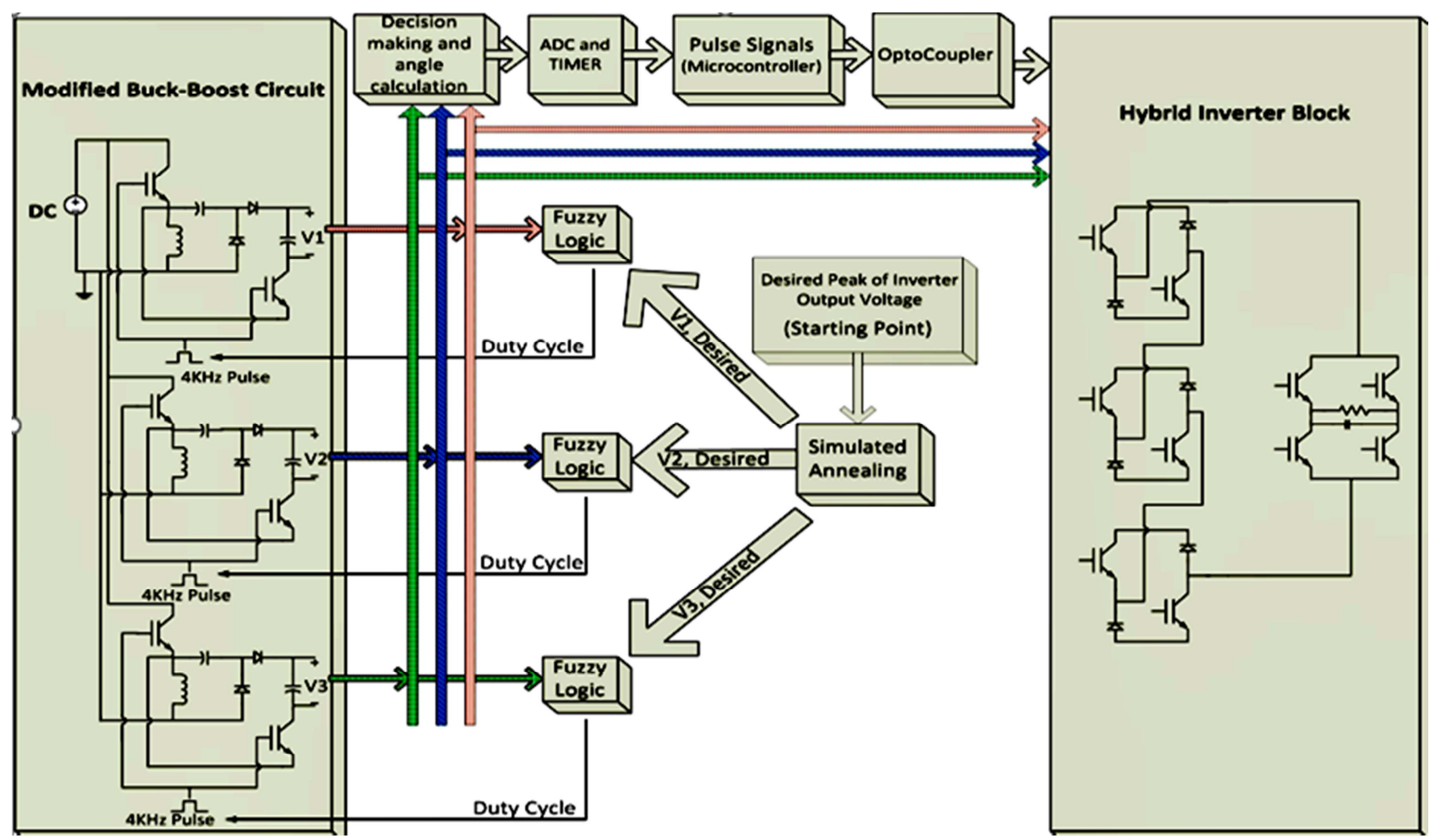

Figure 1. Block Diagram of Proposed Methodology. 


\section{Isolated Buck-Boost Converter}

Operating principles and detailed analysis of overall DCDC converter methodology will be discussed in this section. Starting point of the methodology is the desired peak voltage of inverter output.

\subsection{Simulated Annealing}

In proposed methodology, all possible combinations of addition and subtraction define all the discrete levels at output of multilevel inverter. As the number of levels increases, THD decreases gradually. THD also depends on the values of discrete levels. Simulated Annealing is an artificially intelligent algorithm which optimizes the values of voltage sources. Goal of SA algorithm is to determine possible values of voltages whose combinations exhibits lowest THD for desired number of sources (such as three) for a sinusoidal wave of desired Peak Amplitude $\mathrm{A}_{\mathrm{m}}$.

Algorithm:

Step 1: Randomly choose three random numbers (x, y, z) whose sum is equal to $A_{m}$. Asume, $T=1000 ; i=100$

Step 2: determine all possible combinations: $\{C\}=[0 \mathrm{x} \mathrm{y} \mathrm{z}$ $x+y y+z z+x \quad x-y \quad x-z \quad y-z \quad x+y+z x+y-z y+z-x z+x-y \quad x-y-z \quad x-z-y$ $\mathrm{y}-\mathrm{z}-\mathrm{x}]$

Step 3: Choose unique values from $\{C\}$ and sort them in ascending order.

Step 4: Determine switching angles for all combinations of $\{C\}$ as: $\{\theta\}=\left(\sin ^{-1}\left(\{C\} / A_{m}\right) \frac{180}{\pi}\right)$

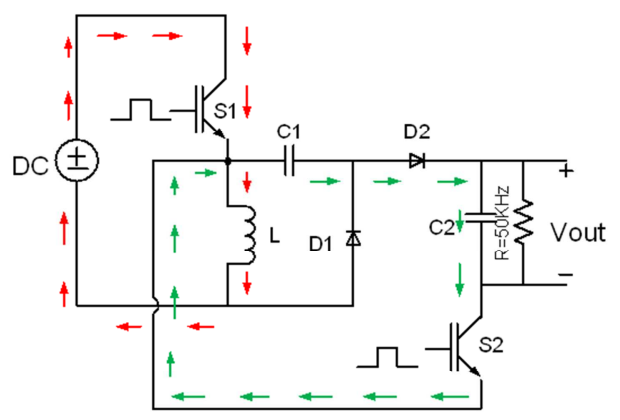

ON Period
Step 5: Formulate a staircase output from $\{C\} \&\{\theta\}$

Step 6: Calculate cumulative mean squared cumulative error, e by comparing desired sinusoidal output and staircase output.

Step 7: Randomly choose another three numbers (xn, yn, zn) and determine error, en following step 1 to step 6 .

Step 8: if en $<=\mathrm{e}$; then $\mathrm{x}=\mathrm{xn}, \mathrm{y}=\mathrm{y}, \mathrm{z}=\mathrm{zn}$

Step 9: if en $>$ e, then if $\exp ^{(e-e n) / T}>$ random number, then $\mathrm{x}=\mathrm{xn}, \mathrm{y}=\mathrm{yn}, \mathrm{z}=\mathrm{zn}$.

Step 10: $\mathrm{T}=\mathrm{T}-\left(\right.$ random number) $\mathrm{T}^{*} *_{\mathrm{i}}$

Step 11: $\mathrm{i}=\mathrm{i}-1$;

Step 12: Repeat Step 2 to Step 11 until $i>=1$

Step 13: x, y, z are the desired values which exhibits lowest THD.

\subsection{Buck-Boost Circuit}

Three isolated Buck-Boost converter is connected to a DC source in parallel. Traditional configuration is slightly modified so that their output nodes are not tied together. Referring to Figure 2(a), During "ON" period, inductor L is charged through switch $\mathrm{S} 1$ while capacitor $\mathrm{C}_{1}$ is discharged through RC parallel branch. During "OFF" period, inductor de-energizes through capacitor, $\mathrm{C}_{1}$ while smoothing capacitor, $\mathrm{C}_{2}$ retains its charged state by partial discharge through large resistance, $\mathrm{R}$. Inductor and capacitors are selected such that energy transfer is in equilibrium state for the desired output voltage.

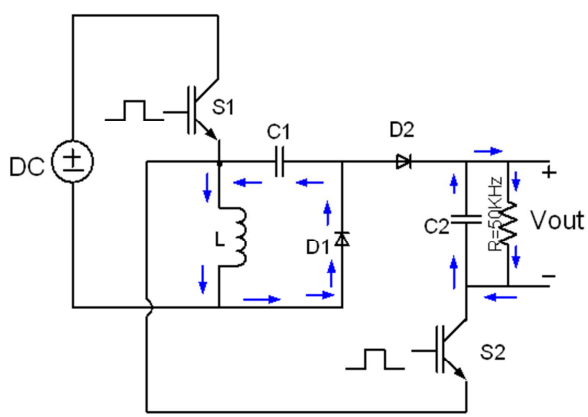

OFF Period

(a) Buck Boost Circuit Current flow at "ON" and "OFF" period

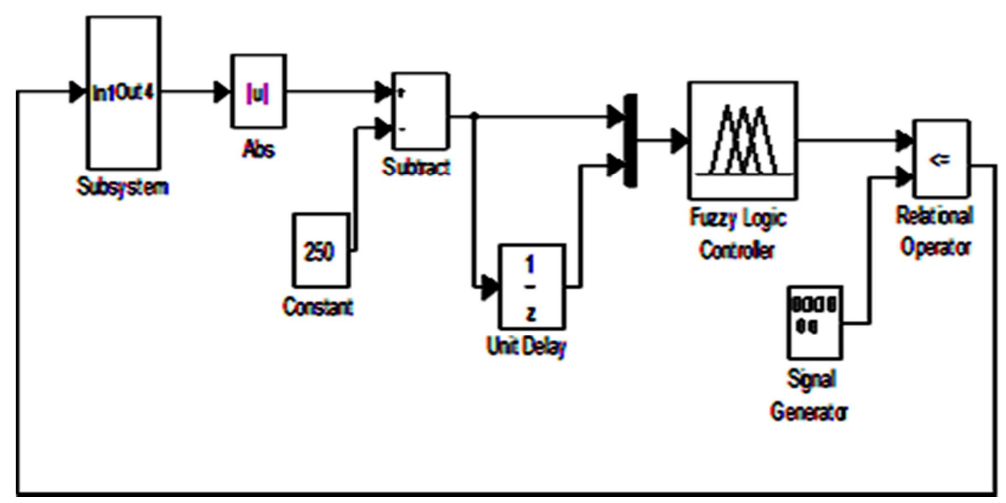

(b) Integration of Fuzzy Logic controller

Figure 2. Operation of Buck Boost Converter. 
Fuzzy Logic system has been integrated with proposed circuit primarily to stabilize voltage near desired voltage level as specified by simulated annealing algorithm. As proposed circuit is nonlinear, Fuzzy logic is more suitable for it than linear control system. Here in Figure 2(b), Subsystem refers to Buck-Boost converter, Out 4 refers to output voltage and in1 refers to switching gate pulse.

\subsection{Hybrid Multilevel Inverter}

Hybridmultilevel inverter consists of cascaded inverter legs where each inverter leg is dependent on upper-left and lower-right switches for its effective inversion. Traditional inverter block is slightly modified to reduce number of switches where upper-right and lower left switches have been replaced by diodes. Instead, only one traditional inverter block has been added which is responsible for overall inversion while cascaded inverter legs are responsible for
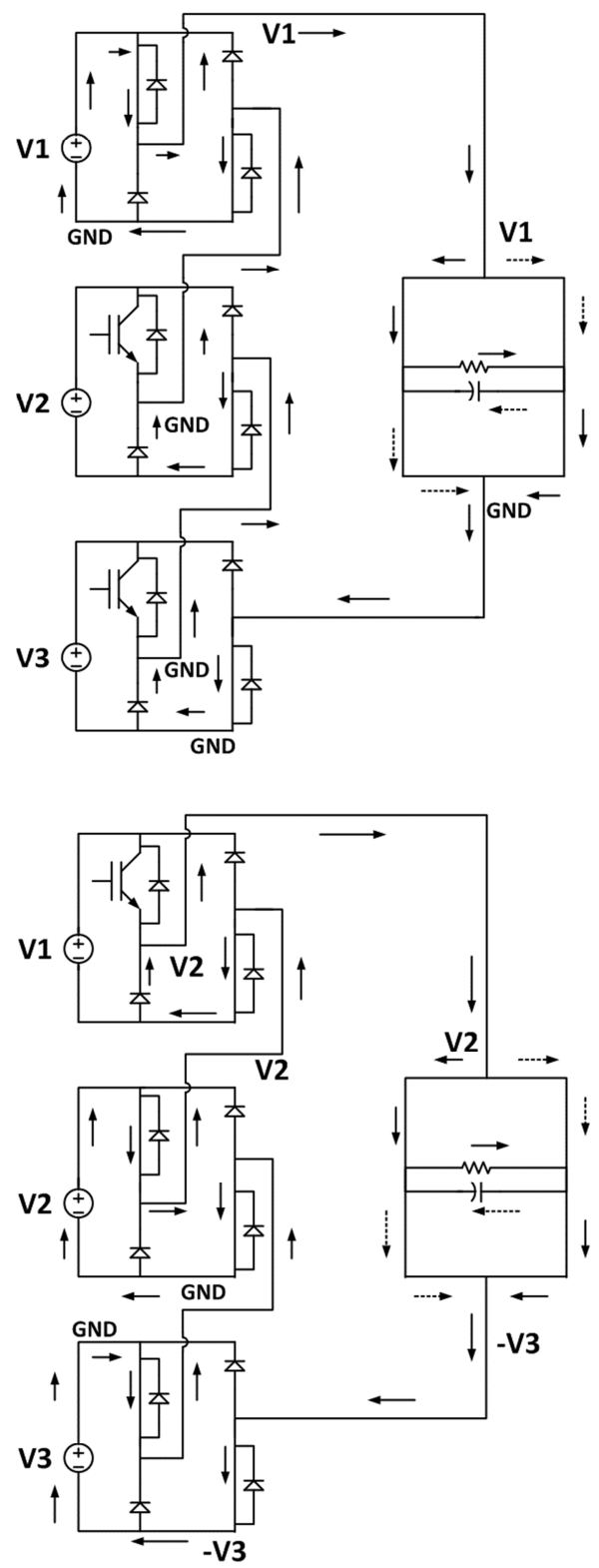

generating all possible arithmetic combinations (addition and subtraction) of voltage levels from isolated sources. The configuration is arranged in such a way that source of greater value is connected to upper inverter leg than source of smaller value. Figure 3 shows circuit configuration and corresponding current flow path for some unique example combinations.

\section{Performance Assessment}

Increased voltage levels reduce THD in output voltage and output current. Figure 4(a) shows performance of SA algorithm at successive iteration. Figure 4(b) shows output voltage where sources are not optimized. Figure 4(c) and Figure 4(d) shows optimized output voltage and corresponding FFT where harmonic distortion has been reduced to $4.6 \%$.
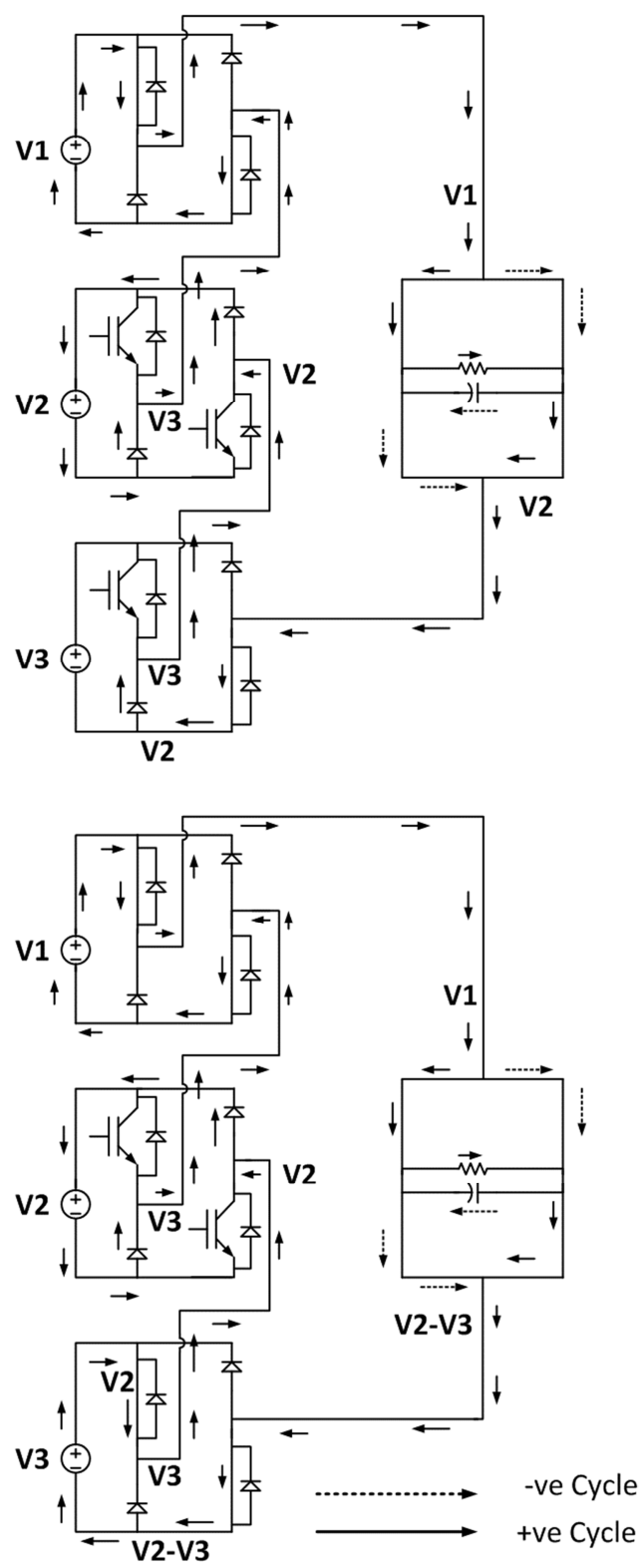

Figure 3. Hybrid multilevel inverter. 


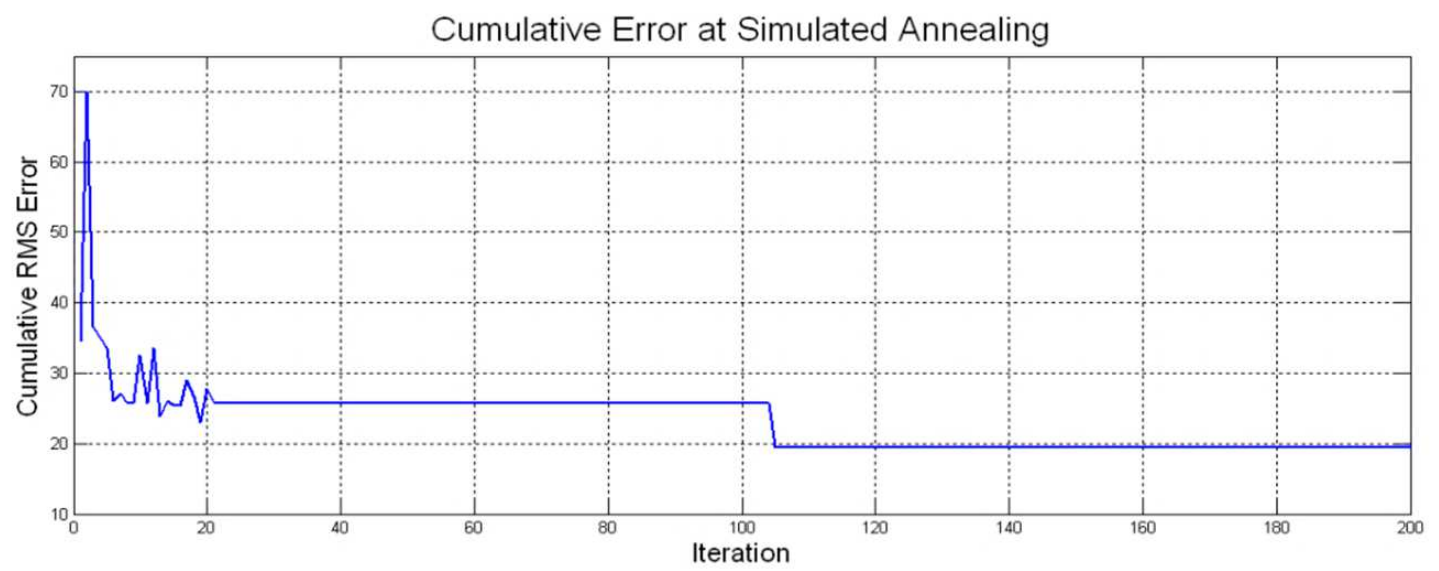

(a) Cumulative Error (THD dependent) Vs Iteration.

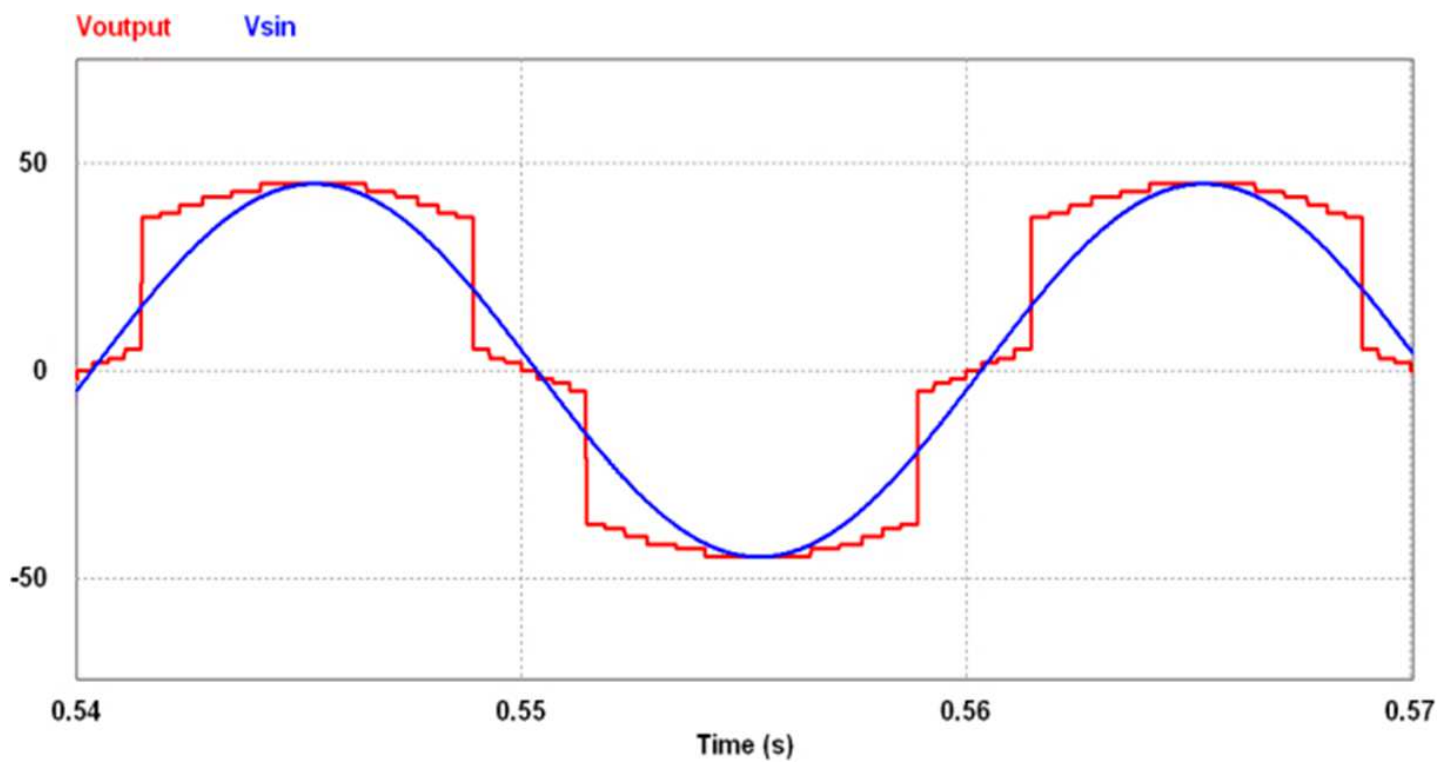

(b) Output voltage without SA algorithm.

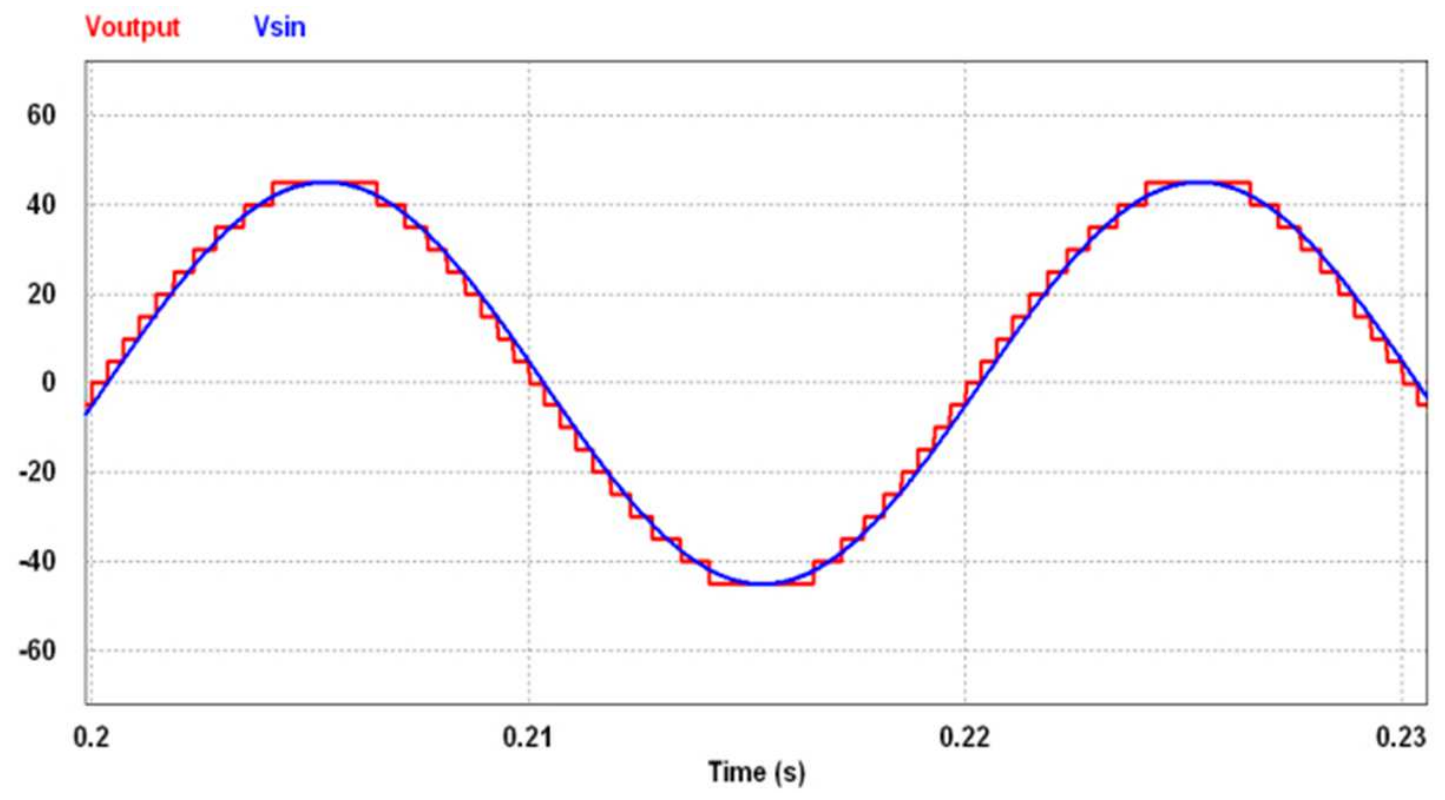

(c) Optimized Output Voltage. 


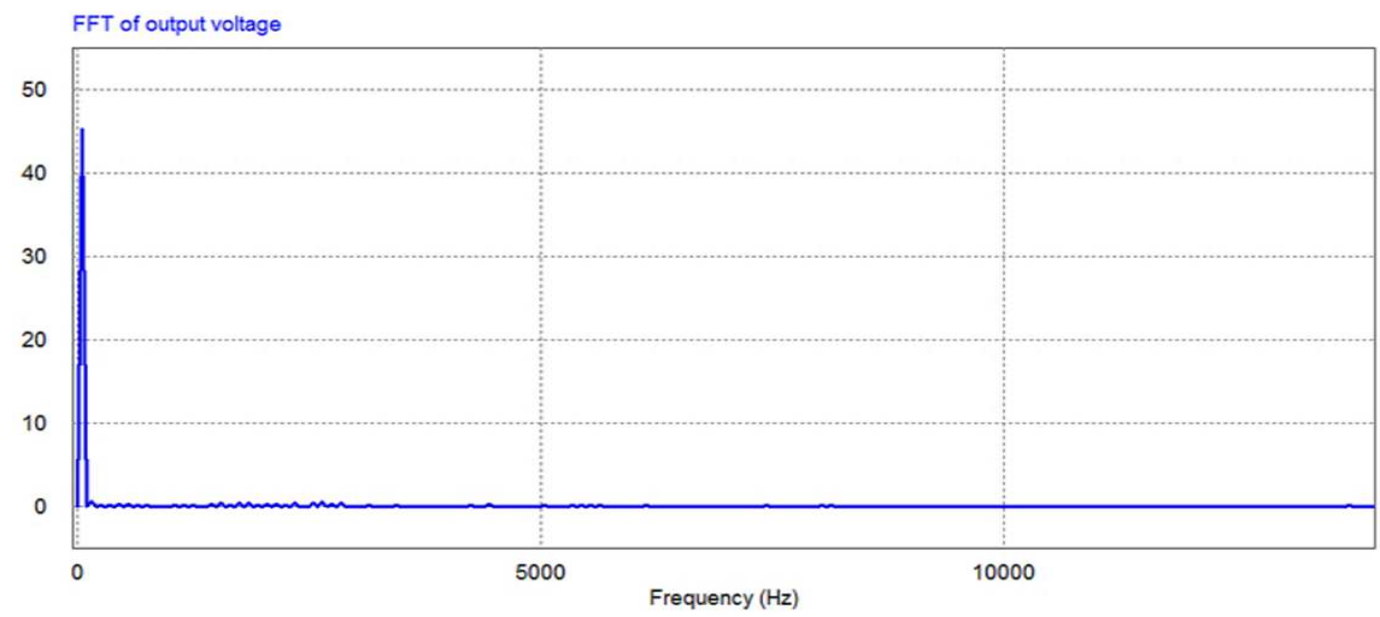

(d) FFT for Optimized Output Voltage.

Figure 4. Performance Assessment.

\section{Conclusion}

This paper illustrates a systematic approach to generate Low THD output power with reduced number of switches from a Single DC source using isolated Buck-Boost inverter. Simulated Annealing algorithm effectively provides a solution to generate lowest possible THD under the constraint of limited number of sources. Additional complexity in pulse generation has been supplanted by the aggrandizement in overall power quality.

\section{References}

[1] Kouro, S.; Malinowski, M.; Gopakumar, K.; Pou, J.; Franquelo, L. G.; Bin Wu; Rodriguez, J.; Perez, M. A.; Leon, J. I., "Recent Advances and Industrial Applications of Multilevel Converters," Industrial Electronics, IEEE Transactions on, vol. 57, no. 8, pp. 2553, 2580, Aug. 2010.

[2] Rodriguez, J.; Jih-Sheng Lai; Fang Zheng Peng, "Multilevel inverters: a survey of topologies, controls, and applications," Industrial Electronics, IEEE Transactions on, vol. 49, no. 4, pp. 724, 738, Aug 2002.

[3] Chiasson, J. N.; Ozpineci, B.; Tolbert, L. M., "A Five-Level Three-Phase Hybrid Cascade Multilevel Inverter Using a Single DC Source for a PM Synchronous Motor Drive," Applied Power Electronics Conference, APEC 2007 - Twenty Second Annual IEEE, vol., no., pp. 1504, 1507, Feb. 25 2007March 12007.

[4] SANG, Zixia, M. A. O. Chengxiong, and Dan WANG. "Comparison on Staircase, PWM and Partial PWM Scheme for Hybrid Cascaded Multilevel Inverter."

[5] KK Gupta, P Bhatnagar. "Multilevel Inverters: Conventional and Emerging Topologies and Their Control", 2017, Elsevier.

[6] Mosazade, S. Y., Fathi, S. H. and Radmanesh, H., 2014. “An overview of high frequency switching patterns of cascaded multilevel inverters suitable for PV applications and proposing a modified method". Indian Journal of Science and Technology, 7 (9), pp. 1342-1349.
[7] McGrath, Brendan Peter, and Donald Grahame Holmes. "Multicarrier PWM strategies for multilevel inverters." IEEE Transactions on industrial electronics 49, no. 4 (2002): 858867.

[8] Malinowski, Mariusz, K. Gopakumar, Jose Rodriguez, and Marcelo A. Perez. "A survey on cascaded multilevel inverters." IEEE Transactions on industrial electronics 57, no. 7 (2010): 2197-2206.

[9] Wu, Bin, and Mehdi Narimani. "Cascaded H-Bridge Multilevel Inverters." High-Power Converters and AC Drives (2006): 119-141.

[10] MSES, Mahmud-Ul-Tarik. "ChowdhuryDesign and Analysis of a Isolated $\mathrm{SiC}$ MOSFET based full-bridge DC-DC converter." 5th ICDRET, Kathmandu, Nepal, March 2018.

[11] MSES, Mahmud-Ul-Tarik. "Design and Simulation of Dual Conversion Transformerless Online and Line-Interactive UPS" International Journal of Sensors and Sensor Networks, vol 7, 2019.

[12] R Girish Ganesan, Mahadevan Bhaskar, K Narayanan, "Novel 11-level Multi-level Inverter", Innovative Smart Grid Technologies - Asia (ISGT Asia) 2018 IEEE, pp. 1050-1055, 2018.

[13] Muhammad Salman, Abdul Basit, Muhammad Shoaib Khalid, Affaq Qamar, "Reduction in Total Harmonic Distortion of Cascaded H-Bridge Multilevel Inverter with Using Phase Method", Power Systems Conference (PSC) 2018 Clemson University, pp. 1-6, 2018.

[14] Muralidhar Nayak Bhukya, Venkata Reddy Kota, Shobha Rani Depuru, "A Simple Efficient and Novel Standalone Photovoltaic Inverter Configuration With Reduced Harmonic Distortion", Access IEEE, vol. 7, pp. 43831-43845, 2019.

[15] Elyazid ZAIDI, Khoudir MAROUANI, Hakim BOUADI, Kamal NOUNOU, Mohamed AISSANI, Larafi BENTOUHAMI, "Control of a Multiphase Machine Fed by Multilevel Inverter Based on Sliding Mode Controller", Environment and Electrical Engineering and 2019 IEEE Industrial and Commercial Power Systems Europe (EEEIC / I\&CPS Europe) 2019 IEEE International Conference on, pp. $1-6,2019$ 